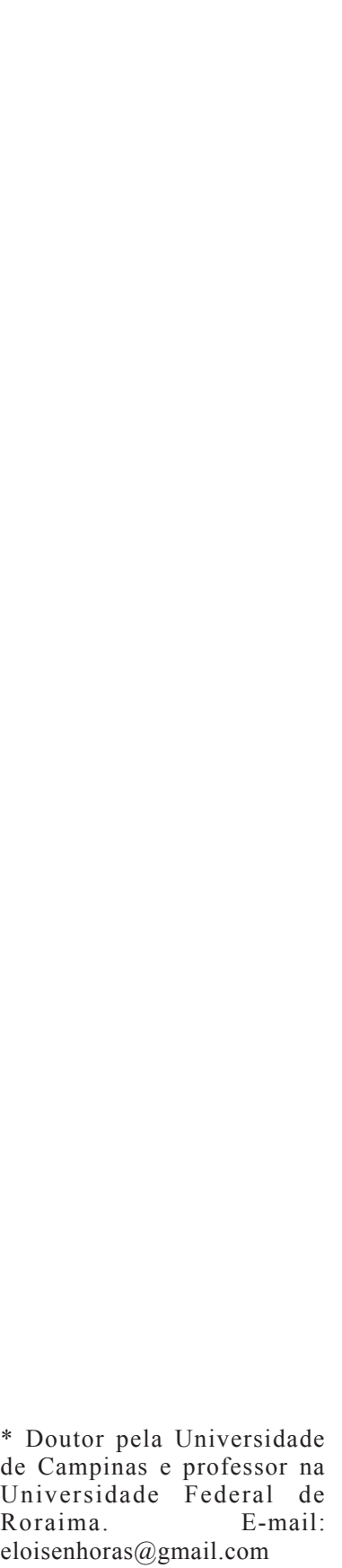

\section{Controvérsias sobre as relações negociais com o setor público: um estudo sobre a terceirização no Brasil}

\author{
Polemics ON BUSINESS RELATIONSHIPS WITH \\ THE PUBLIC SECTOR: AN OUTSOURCING STUDY IN \\ BRAZIL
}

Eloi Martins Senhoras *

Resumo: O presente artigo discute o processo de terceirização, tomando como referência uma pesquisa jurídica de revisão e de natureza exploratória, cujo objetivo foi desenvolver uma análise da evolução da terceirização na Administração Pública no Brasil, com base em marcos doutrinários e normativos, a fim de demonstrar a partir de uma lógica dedutiva que a polêmica produzida por discursos contrários e a favor tem repercussão conflitante, mesmo quando canalizada pela jurisprudência do Tribunal Superior do Trabalho (TST) e do Supremo Tribunal Federal (STF), já que não existe uma legislação específica no país.

Palavras-chave: Administração Pública. Responsabilidade subsidiária. Terceirização.

Abstract: The present article discusses the outsourcing process, taking as reference a legal research of review and exploratory nature, whose objective was to develop an analysis of the outsourcing evolution at the Brazilian Public Administration, with bases on doctrinal and normative milestones, with ends to demonstrate from a deductive logic that the controversy generated by arguments against and in favor have a conflicted repercussion, even when canalized by the jurisprudence of the Superior Labor Court (TST) and the Supreme Federal Court (STF), since there is no specific legislation in the country.

Keywords: Public Administration. Subsidiary responsibility. Outsourcing. 


\section{INTRODUÇÃO}

A terceirização é um processo administrativo que pode ser compreendido pela transferência de determinadas atividades-meio - de natureza periférica, acessória ou marginal em uma organização -, em benefício de um empreendedor autônomo ou outra organização que seja especializada e as tenha como atividadefim.

O processo de repasse de atividades secundárias a empresas terceiras, vulgarmente conhecido pela denominação de terceirização, se refere a um padrão de flexibilização organizacional, pública e privada, que busca aumentar a eficiência por meio de uma concentração ontológica àquelas atividades que compõem o núcleo estratégico de cada organização no contrato, já que determinadas atividades-meio para uma parte representam atividades-fim para outra parte.

A estratégia da terceirização faz parte de um grande movimento de flexibilização e desregulamentação do Direito do Trabalho no contexto de esgotamento do Estado Keynesiano, cuja lógica é não apenas abrandar a rígida regulação trabalhista, mas também otimizar ganhos de eficiência com base em uma perspectiva gerencial de aumento de produtividade e de redução de custos.

Embora as estratégias de terceirização tenham sido trazidas ao Brasil por empresas multinacionais, por meio da contratação de empresas de conservação e limpeza, foi justamente a Administração Pública que primeiro se utilizou de serviços terceirizados em razão do Decreto-Lei n 200 (BRASIL, 1967) que trazia uma Reforma Administrativa e propiciava meio de contratação sem a necessidade de se realizar concursos para atividades não essenciais do Estado, mesmo a regulamentação da terceirização tendo surgido, apenas com a Lei 6.019 (BRASIL, 1974).

Mas é somente a partir da década de 1990 que a Administração Pública brasileira vai se utilizar de maneira sistemática da terceirização como um conceito basilar funcional para a nova reforma administrativa a fim de se buscar na colaboração com prestadores de serviços especializados, maior economia em recursos humanos e otimização do rendimento do trabalho, momento em que surge uma série de polêmicas sobre o uso deste instituto pelo poder público (SOUTO, 2001).

Tomando como referência estas discussões, o objetivo da pesquisa é avaliar o significado teleológico e as polêmicas derivadas da implementação da estratégia de terceirização na Administração Pública, por meio de uma discussão 
que foi estruturada em três recortes basilares, os quais se inter-relacionam, findando, como macro-objetivo, desenvolver um balanço sobre os marcos doutrinários e jurisdicionais para o caso brasileiro.

$\mathrm{Na}$ primeira seção, "Debates sobre a terceirização na Administração Pública", são explorados marcos jurídico-conceituais e os principais debates entre especialistas e doutrinadores a fim de mostrar a divisão existente a favor e contra a adoção da terceirização como meio de desverticalização de serviços e atividades operacionalizados pela máquina pública.

$\mathrm{Na}$ segunda seção, "Periodização contextual da terceirização na Administração Pública", o artigo mostra a partir de uma análise de longa duração como a terceirização se difunde em diferentes tempos no sistema internacional até chegar ao Brasil em função de questões estruturais de natureza exógena, relacionadas à difusão do paradigma neoliberal e às mudanças nos padrões de produção e trabalho.

$\mathrm{Na}$ terceira seção, "Marcos doutrinários e jurisprudenciais sobre a terceirização na Administração Pública brasileira", delineamentos sobre licitude na terceirização na Administração Pública e discussões doutrinárias sobre responsabilidade subsidiária são trazidos ao debate à luz dos principais marcos jurídicos sobre a terceirização, regulamentada, apenas em 1974, como atividade temporária, até chegar à Súmula 331, com devidas revisões, do Tribunal Superior do Trabalho (TST).

Por fim, "Últimas considerações" à guisa de conclusão são trazidas como argumentos finais, porém não menos importantes, pois, tanto, retomam conceitos e debates centrais discutidos ao longo do texto, quanto, prospectam o futuro da terceirização na Administração Pública com base em projetos de lei em tramitação no Congresso Nacional.

\section{DEBATES SOBREA TERCEIRIZAÇÃO NAADMINISTRAÇÃO PÚBLICA}

No caso da crescente utilização da terceirização pela Administração Pública, verifica-se que ela tem sido alvo de polêmico debate entre especialistas e doutrinadores que se dividem a favor e contra a adoção desta prática contratual de desverticalização de serviços e atividades operacionalizados pela máquina pública lato sensu.

De um lado, a terceirização como política de eficiência da Administração Pública representa um esforço de enxugamento do quadro de servidores 
pertencentes à máquina pública com o objetivo de reduzir os gastos estatais àquelas atividades consideradas estratégicas e de monopólio do Estado.

Segundo esta perspectiva minimalista sobre o tamanho da máquina pública, existe uma interpretação positiva sobre a parceria entre as iniciativas pública e privada como uma opção de flexibilização trabalhista adequada às mudanças existentes no mundo do trabalho e às necessidades de um Estado logístico que busca aumentar a eficiência da prestação dos serviços públicos ${ }^{1}$.

Em uma primeira perspectiva, alguns especialistas argumentam que a previsão legal de utilização de contratos com empresas privadas deve se restringir àquelas atividades-meio, de natureza acessória ou complementar ao núcleo primário-estratégico da máquina pública, cuja execução é apenas colaborativa ao desenvolvimento das políticas públicas.

Em uma segunda perspectiva, outros especialistas defendem que a terceirização não deve se restringir apenas às atividades-meio, pois os atuais marcos jurídicos tomam como referência um critério absoluto de legalidade em um contexto no qual, crescentemente, se torna difícil distinguir atividades-meio de atividades-fim devido ao grau de complexidade das mesmas e da mutabilidade das competências exigidas no trabalho (DINIZ, 1999; MARTINS, 2003; PASTORE, 2006).

De outro lado, a terceirização como política de privatização da Administração Pública trata-se de uma leitura existente entre especialistas e doutrinadores que busca mostrar que a transferência de atividades não estratégicas ao funcionamento da máquina administrativa e ao desenvolvimento de políticas públicas para o setor privado acaba por convalidar uma lógica de privatização das relações de trabalho, que eventualmente, reduz custos, mas não necessariamente aumenta a qualidade ou a eficiência produtiva.

Esta interpretação negativa sobre a terceirização, em especial, na Administração Pública, está respaldada pela análise fática dos variados casos em que empresas terceirizadas prestam atividades e serviços técnicos especializados, embora com significativa deterioração das condições de trabalho dos empregados, os quais muitas vezes, eram, anteriormente, empregados como servidores públicos na execução das mesmas funções (DI PIETRO, 2006; SOUTO MAIOR, 2006; POCHMANN, 2008).

\footnotetext{
${ }^{1}$ A defesa da terceirização na Administração Pública embasada em um paradigma liberal busca nesse processo uma forma flexível de desburocratização da máquina estatal que propicie ao Estado se concentrar naquelas atividades essenciais.
} 
A terceirização na Administração Pública se dinamizou como política de privatização em função de vícios pré-existentes no aparelho estatal, a fim de deter o crescimento desmesurado da máquina administrativa e de se burlar os limites de gastos com pessoal estabelecido a Lei de Responsabilidade Fiscal, o que repercute em um desvirtuamento na prestação de trabalho, com efeitos negativos em termos de corrupção similares à desenvolvimento de anéis burocráticos por meio da contratação exacerbada de servidores comissionados ${ }^{2}$.

Destarte, os argumentos contra a terceirização identificam que esta prática tornou-se crescentemente suscetível à corrupção, particularmente na Administração Pública, uma vez que são identificadas fraudes em licitações e concursos públicos, bem como, estratégias de downsizing por parte de subcontratações que impactam na redução de postos de trabalho, no aumento da carga de trabalho e na perda de direitos para o trabalhador.

Não obstantes as diferentes interpretações a favor e contra, observa-se que tanto, no setor privado, quanto, no setor público, a temática dos contratos de terceirização, é um tema amplamente debatido no mundo, em especial no Brasil que não possui legislação específica, uma vez que há uma contraditória tendência promovida ela difusão de redes de produção e serviços em diversos países desenvolvidos e emergentes vis-à-vis aos questionamentos de deterioração dos condicionantes legais de trabalho (CORTEZ, 2004).

\section{PERIODIZAÇÃO CONTEXTUAL DA TERCEIRIZAÇÃO NA ADMINISTRAÇÃO PÚBLICA}

A função teleológica da terceirização é alcançar maior qualidade, produtividade e redução de custos por meio do desenvolvimento de uma parceria que promova a concentração do contratante naquelas atividades e serviços que compõem seu objetivo final, evitando a dispersão em atividades de apoio, as quais passam a serem executadas pelas empresas terceirizadas.

Conforme Sekido (2010), a terceirização tem sido objeto de estudo a décadas, por diferentes correntes e ramos do conhecimento, motivo pelo qual surgiram diferentes maneiras de classificá-la, quanto à forma (interna ou externa); ao estágio (inicial, intermediária ou avançada); ao objeto (serviços, materiais,

\footnotetext{
${ }^{2}$ A evolução da terceirização, acompanhada da contratação hipertrofiada de servidores comissionados representa uma bula recorrente ao instituto do concurso público no país, descrevendo, nos casos de corrupção a manutenção de um padrão descentralizado de relações viciadas que são marcadas pela subjetividade e a anéis burocráticos de natureza não meritocrática.
} 
equipamentos, atividades produtivas e tecnológicas), à finalidade (mão de obra, risco, parceria) e ao status (lítica ou ilícita).

[As atividades-meio mais suscetíveis de terceirização no mundo] estão nas áreas de informática, organização e métodos, serviços jurídicos, relações públicas, recrutamento e seleção, treinamento e desenvolvimento, administração de cargos e salários, folha de pagamento, benefícios em geral, restaurante e alimentação, previdência privada, saúde, seguro de vida e acidentes, transporte coletivo, limpeza e conservação, segurança, gráfica, correio externo, malote, frota de veículos, importação e exportação, auditoria de sistemas, marketing, pesquisa de mercado, propaganda, projetos, laboratórios diversos e serviços domésticos" (PASTORE, 2006, p.5).

Esta forma de contratação denominada terceirização é uma tendência existente desde a década de 1950, mas que se manifestou, em diferentes países em distintas décadas, com os objetivos convergentes de otimizar determinadas atividades-meio, diminuir riscos e custos trabalhistas e previdenciários, bem como aumentar a taxa de lucratividade.

Inicialmente, denominado como contratação de atividades e serviço de terceiros, o processo de terceirização somente passou a adquirir esta denominação por meio da construção legiferante da terminologia em vários países frente ao contexto de difusão desta tendência administrativa de desverticalização da produção.

Hoje, as atividades exercidas por prestadores de serviços e autônomos tem sido popularmente conhecidas pelo jargão de "atividades terceirizadas", uma vez que a difusão de processos de terceirização engendrada pelo modo de produção enxuta e pelas ondas de políticas neoliberais no mundo impulsionou o surgimento empresas terceirizadas por parte daquelas organizações que buscavam reduzir seus custos e riscos operacionais de atividades que não pertenciam ao núcleo duro dos negócios.

Em primeiro lugar, a passagem do paradigma tecno-científico da produção em massa para o paradigma da produção enxuta, contextualizada com a difusão de inovações significativas em logística e em tecnologias de informação e comunicação, acabou por ser funcional para o desenvolvimento de terceirizações.

Destarte, muitas atividades que antes eram endogenizadas nas organizações, passaram crescentemente por um movimento de outsorcing, o que refletiu na busca externa por empresas parceiras com a finalidade de diminuir 
os custos de transação por meio de redes focalizadas na promoção de atividadesmeio (FILADELFO, 2011).

Em segundo lugar, a passagem do paradigma keynesiano, marcado por políticas estatais intervencionistas, para um paradigma liberal, de Estado mínimo, impulsionou um boom de privatizações e terceirizações em razão da passagem de atividades enquadradas como não pertencentes ao core business para a iniciativa privada.

Há que se observar que a temática da terceirização por parte da Administração Pública necessariamente incorre em uma hierarquização axiológica sobre o conteúdo e funções das políticas públicas, a qual incorre em um movimento hermenêutico pendular entre minimalismo e maximalismo estatal ao longo do tempo que reflete os ciclos de predominância dos paradigmas liberal e intervencionista.

Internacionalmente, o ritmo da difusão dos processos de terceirização aconteceu assimetricamente no espaço e no tempo por meio de ondas neoliberais, uma vez que na década de 1970, se difundiu com o surgimento do neoliberalismo nos Estados Unidos e Inglaterra, mas também, no Chile; na década de 1980, no Leste Asiático, na década de 1990, com as reformas na América Latina, e, a partir, do final da década de 2000 na Europa.

No Brasil, a simultaneidade da difusão do neoliberalismo político, com a entrada no paradigma da produção enxuta, com a abertura comercial, impactou em um ajuste econômico penoso que repercutiu em processos de redução do número de empregos com os enxugamentos organizacionais (downsizing) que foram, parcialmente, compensados com a tendência de abertura de empregos em empresas terceirizadas.

\section{MARCOS DOUTRINÁRIOS E JURISPRUDENCIAIS SOBRE A TERCEIRIZAÇÃO NA ADMINISTRAÇÃO PÚBLICA BRASILEIRA}

Quando se leva em conta a análise jurídica sobre o fenômeno da terceirização, faz-se necessária uma compreensão conceitual que se tornou consagrada na doutrina e na jurisprudência sobre as atividades e as hierarquizações do empregador, a fim de mostrar a sua legalidade ou ilegalidade, quando contratada sob responsabilidade da Administração Pública.

De um lado, as atividades organizacionais, quando classificadas como atividades-fim (funções nucleares) e atividades-meio (funções auxiliares) 
demonstram as situações possíveis de contratação de autônomos e prestadores de serviços por parte da Administração Pública (BONFIGLIOLI, 2011).

A atividade-fim é aquela que demonstra qual a finalidade principal do negócio organizacional, podendo ser melhor compreendida quando lidos o contrato social, legislação ou regimento interno da organização, onde é possível visualizar o registro do objetivo social.

A atividade-meio, por sua vez, refere-se a toda ação acessória ou mesmo correlata, que tem natureza não-finalística no negócio organizacional, motivo pelo qual, tem importância interna, embora seja suscetível de externalização por meio de contratos com prestadores de serviços e autônomos.

De outro lado, as hierarquizações organizacionais revelam os custos de transação entre endogenização e exogenização das atividades, os quais incorrem, necessariamente, em uma escolha compensatória (trade-off) para a existência ou não de relações de pessoalidade e subordinação.

A escolha compensatória pode ser compreendida pelo entendimento doutrinário e jurisprudencial que admite que determinada organização contrate outra organização prestadora de serviços caracterizados como atividades-meio, porém, sem existir vínculos de pessoalidade e subordinação direta.

Da perspectiva contrária, não ocorrendo terceirização da prestação dos serviços, persiste a funcionalidade dos institutos da pessoalidade - prestação de serviço que manifesta desde o contrato intuito personae -, e, da subordinação - dependência jurídica das ordens do empregador.

Tomando como referências as atividades e as hierarquias no processo de terceirização, observa-se que determinados conceitos e institutos são limitadores na Administração Pública ${ }^{3}$ com base no que é lícito ou ilícito, demonstrando assim que a terceirização somente é admitida para atender a situações específicas e justificadas em que haja, tanto, uma natureza não continuada, quanto, uma necessidade advinda de profissionais do órgão.

Segundo um prisma, é considerada lícita toda aquela terceirização que se caracterize como atividade-meio, ou seja, aquela que venha a corroborar, apenas, para as atividades finais do serviço público, uma vez que possui uma natureza de suporte ou apoio às atividades principais, gerando a responsabilidade subsidiária do tomador por eventuais créditos do trabalhador não saldados pelo fornecedor dos serviços.

\footnotetext{
${ }^{3}$ Diferentemente das pessoas jurídicas de direito privado, a quem é lícito fazer tudo aquilo que a lei não proíbe, a Administração Pública submete-se ao princípio da legalidade, impondo aos servidores públicos agirem com discricionariedade estrita ao que estiver previsto em lei, motivo pelo qual enfrenta maiores restrições na contratação de serviços terceirizados (SILVA, 2008).
} 
Segundo outro prisma, é considerado ilícito qualquer tipo de terceirização de atividade-fim na Administração Pública, já que esta se caracteriza por uma ação essencial, possuindo, assim, uma natureza nuclear para a prestação das políticas públicas, o que torna nulo o liame jurídico entre o trabalhador e o fornecedor de seus serviços, gerando vínculo empregatício diretamente entre o trabalhador e o tomador de seus serviços (HINZ, 2005).

Nos processos de terceirização, cabe perguntar, se, tanto, nos casos de licitude, quanto de ilicitude, se haverá algum tipo de responsabilidade da Administração Pública ${ }^{4}$ para com o trabalhador, uma vez que entre ambos não há uma relação contratual direta, mas, antes, apenas, uma relação que é intermediada pela organização prestadora dos serviços.

De um lado, interpreta-se que o processo de terceirização de serviços gera entre as partes diretamente envolvidas - tomadora e fornecedora - uma série de direitos e obrigações, como em qualquer relação contratual, embora existam, também, responsabilidades subsidiárias entre a Administração Pública, como tomadora de serviços para com o trabalhador.

Conforme Kich (2010), os tribunais brasileiros adotam, sistematicamente, a responsabilidade subsidiária às organizações contratantes, como premissa de garantia aos trabalhadores, nos casos de terceirização de serviços em que surjam lacunas de prestação nos haveres trabalhistas por parte das empresas prestadoras, motivo pelo qual, a Administração Pública e a maior parte das grandes, pequenas e médias empresas se preocupam em verificar nas empresas contratadas se elas cumprem, em primeiro lugar, com os encargos trabalhistas, e, em segundo lugar, com as normas de saúde e segurança no trabalho.

Esta percepção sobre a responsabilidade subsidiária da Administração Pública surge em um recente contexto, marcado por lenta evolução ${ }^{5}$ dos marcos jurídicos brasileiros sobre o fenômeno da terceirização, o qual,

\footnotetext{
${ }^{4}$ Conforme Silva (2011), embora, a Constituição Federal de 1988 traga no artigo 37 , § $6^{\circ}$, a responsabilidade civil objetiva do Estado quanto às pessoas jurídicas de direito público $\mathrm{e}$ as de direito privado prestadoras de serviços públicos, a Lei $\mathrm{n}^{\circ}$ 8.666, na contramão, criou um paradoxo na Administração Pública, ao promover a liberação deste de toda e qualquer responsabilidade objetiva em face do inadimplemento das verbas trabalhistas, razão pela qual, estas têm sido tradicionalmente trabalhadas pela ótica da responsabilidade subjetiva.

${ }^{5}$ A identificação de uma lenta evolução dos marcos jurídicos sobre a terceirização no Brasil parte de uma compreensão histórica de que não existiu uma tendência de linearidade, mas, antes, incorreu em uma série de fricções e descontinuidades ao longo do tempo em relação às perspectivas legiferante e hermenêutica, haja vista que a desconstrução do paradigma cognitivo do intervencionismo nacionalrealista pelo emergente paradigma do laissez faire neoliberal no país aconteceu em função da passagem de um regime ditatorial para democrático, na qual há, por conseguinte, uma clara ruptura dos próprios paradigmas econômicos, sociais e jurídicos.
} 
inicialmente, passa a ser regulamentado, apenas, em 1974, como uma atividade temporária, até se tornar passível de prestação nos serviços públicos na década de 1990, por meio das Leis 8.987 e 9.472, bem como da Súmula 331 do Tribunal Superior do Trabalho (TST).

O instituto da responsabilidade subsidiária da Administração Pública aparece nas revisões textuais de 2000 e 2011 da Súmula 331 do TST, com a previsão de que os entes públicos integrantes da administração direta e indireta respondem subsidiariamente ao trabalhador quanto às obrigações trabalhistas, desde que tenham participado da relação processual e constem também do título executivo judicial, conforme Lei n ${ }^{\circ} .8 .666$ (BRASIL, 1993).

De acordo com Martins (2003), a responsabilidade subsidiária da Administração Pública, como contratante de empresas terceirizadas, vem a atender à necessidade de segurança das relações de trabalho com relação ao hipossuficiente, em razão de uma questão fática in eligendo, quando decorrente de culpa da empresa contratada, ou in vigilando, quando a própria Administração Pública apresentar um comportamento deficitário de má escolha ou fiscalização de seu parceiro.

Quadro 1 - Principais marcos jurídicos sobre a terceirização no Brasil

\begin{tabular}{|c|c|c|}
\hline 1974 & Lei 6.019 & $\begin{array}{l}\text { Conhecida, como lei do trabalho temporário, regulamentou o } \\
\text { fenômeno da terceirização, como atividade temporária. }\end{array}$ \\
\hline 1983 & Lei 7.102 & $\begin{array}{l}\text { Regulamentou o trabalho de vigilância bancária, a partir da } \\
\text { identificação da terceirização como uma atividade permanente. }\end{array}$ \\
\hline 1993 & Lei 8.666 & Regulamentaram a terceirização na Administração Pública por \\
\hline 1995 & Lei 8.987 & meio do regime de concessão e permissão da prestação de \\
\hline 1997 & Lei 9.472 & serviços públicos. \\
\hline 1986 & $\begin{array}{c}\text { Súmula } 256 \\
\text { do TST }\end{array}$ & $\begin{array}{l}\text { Regulamentou a legalidade e ilegalidade dos contratos de serviços } \\
\text { no Brasil. A Súmula } 256 \text { foi cancelada por ter sido revista e } \\
\text { ampliada pela Súmula } 331\end{array}$ \\
\hline 1993 & \multirow{3}{*}{$\begin{array}{c}\text { Súmula } 331 \\
\text { TST }\end{array}$} & \multirow{3}{*}{$\begin{array}{l}\text { Principal marco normativo do instituto da terceirização trabalhista } \\
\text { no país, revista, em } 2000 \text { e em 2011, com redação final em } \\
\text { 31/05/2011. }\end{array}$} \\
\hline 2000 & & \\
\hline 2011 & & \\
\hline
\end{tabular}

Fonte: Elaborado pelo autor. Baseada nãos marcos legais supracitados

De outro lado, existe uma leitura sobre a natureza do ato jurídico dos contratos de terceirização dos serviços, que prevê a inexistência de responsabilidade subsidiária da Administração Pública em relação aos trabalhadores no caso de inadimplência, uma vez que as partes diretamente envolvidas na prestação e na contratação teriam, apenas, direitos e obrigações entre si. 
Com base nesta doutrina, surgiu a decisão favorável do Supremo Tribunal Federal (STF) à Ação Declaratória de Constitucionalidade (ADC), número 16/ 2010, que manifesta que os entes públicos não podem ser responsabilizados pelos encargos trabalhistas, fiscais e comerciais decorrentes da terceirização, o que repercutiu na formação de nova jurisprudência sobre o assunto (SIROTHEAU, 2011).

Em razão da jurisprudência do STF sobre o tema, surgiu uma nova redação da Súmula 331 do TST no ano de 2011, que manifestou não poder haver generalização dos casos no tocante à responsabilidade subsidiária da Administração Pública, motivo pelo qual se faz necessário investigar com rigor os casos de inadimplência do fornecedor de serviços em que a causa principal seja falha ou falta de fiscalização pelo órgão público contratante.

Box 1 - Súmula 331 do Tribunal Superior do Trabalho

\section{CONTRATO DE PRESTAÇÃO DE SERVIÇOS. LEGALIDADE}

I - A contratação de trabalhadores por empresa interposta é ilegal, formando-se o vínculo diretamente com o tomador dos serviços, salvo no caso de trabalho temporário (Lei no 6.019, de 03.01.1974).

II - A contratação irregular de trabalhador, mediante empresa interposta, não gera vínculo de emprego com os órgãos da Administração Pública direta, indireta ou fundacional (art. 37, II, da CF/1988).

III - Não forma vínculo de emprego com o tomador a contratação de serviços de vigilância (Lei no 7.102, de 20.06.1983) e de conservação e limpeza, bem como a de serviços especializados ligados à atividade-meio do tomador, desde que inexistente a pessoalidade e a subordinação direta.

(Nova redação em 18/09/2000)

WV = O inadimplemento das obrigações traballhistas, por parte do empregator; impliea a responsabilidade subsidiária do tomador dos serviȩos, quanto àquelas obrigaęões, inelusive quanto aos órgãos da administração direta, das autarquias, tas fundações públieas, das empresas públieas e das soeiedades de economia mista, desde que hajam partieipado da relaȩão proeessuale eonstem também do títtloexeeutivo judieial (art. 71 da Lei no 8.666, de 21.06.1993).

(Nova redação em 24/05/2011)

IV - O inadimplemento das obrigações trabalhistas, por parte do empregador, implica a responsabilidade subsidiária do tomador de serviços quanto àquelas obrigações, desde que haja participado da relação processual e conste também do título executivo judicial. 
(Itens V e VI, acrescentados em 24/05/2011)

$\mathrm{V}$ - Os entes integrantes da administração pública direta e indireta respondem subsidiariamente, nas mesmas condições do item IV, caso evidenciada a sua conduta culposa no cumprimento das obrigações da Lei n. 8.666/93, especialmente na fiscalização do cumprimento das obrigações contratuais e legais da prestadora de serviço como empregadora. A aludida responsabilidade não decorre de mero inadimplemento das obrigações trabalhistas assumidas pela empresa regularmente contratada.

VI - A responsabilidade subsidiária do tomador de serviços abrange todas as verbas decorrentes da condenação.

Fonte: Brasil (2011).

Compreende-se que a nova redação da Súmula 331 do TST, ao manter a responsabilidade subsidiária da Administração Pública nos processos de contratação de serviços terceirizados, em condições específicas, acabou por contrariar a decisão do STF no julgamento da ADC 16/2010, favorável à constitucionalidade da Lei 8.666/1993, artigo $70, \S 1^{\circ}$, redigida in verbis:

A inadimplência do contratado, com referência aos encargos trabalhistas, fiscais e comerciais não transfere à Administração Pública a responsabilidade por seu pagamento, nem poderá onerar o objeto do contrato ou restringir a regularização e o uso das obras e edificações, inclusive perante o Registro de Imóveis (BRASIL, 1993).

A modificação da Súmula 331, ao procurar ajustar a jurisprudência do TST sobre a legalidade dos processos de terceirização na Administração Pública, em resposta à decisão na ADC 16 do STF, claramente desfavorável ao trabalhador, acabou por gerar uma situação de aparente conflito com a instância superior (jurisprudência contra legem), por justamente manter a responsabilidade pública da Administração, o que tenderá a levar a demandas judiciais em última instância do trabalhador a fim de obter um pronunciamento final do STF.

\section{CONSIDERAÇÕES FINAIS}

Com base nestas discussões, a favor e contra a responsabilidade subsidiária da Administração Pública, chega-se ao entendimento sintético dos marcos da ADC 16/2010 e da Súmula 331/2011 de que o Poder Público lato sensu nem sempre responderá subsidiariamente no caso daquelas terceirizações, 
lícitas ou ilícitas, em que as empresas prestadoras não venham a quitar os haveres trabalhistas de seus empregados.

A partir destes marcos legais, identifica-se a positividade legal da exigência de comprovação fática nos casos problemáticos de terceirização em que se reinvidica responsabilidade da Administração Pública, uma vez que a subsidiariedade trabalhista passa a não ser automática, quando a empresa contratada - prestadora serviços - vier a não cumprir suas obrigações trabalhistas com seus empregados.

Não é por acaso que a responsabilidade subsidiária da Administração Pública por obrigações trabalhistas geradas por inadimplência de empresas terceirizadas seja o tema com maior número de processos sobrestados no TST, $45 \%$ do total existente em 2012, já que se trata do tema com maior repercussão por ter relevância geral de natureza multidimensional e que ultrapassa os interesses das partes envolvidas (BRASIL, 2012).

As influências dos ultra-recentes marcos de jurisprudência superior no TST e no STF relacionados à terceirização na Administração Pública têm tido ampla repercussão sobre os Poderes Executivo e Legislativo, de maneira a se registrar a edição de instruções e acórdãos embasando-se em decisões do Poder Judiciário.

No Poder Executivo, a discricionariedade de contratações terceirizadas na Administração Pública é disciplinada pelas Instruções Normativas $n^{\circ} 2$ e $n^{\circ}$ 3 do Ministério do Planejamento, Orçamento e Gestão (MPOG), as quais, objetivam criar, tanto freios, quanto multiplicadores do processo, conforme os marcos legais do Judiciário e conveniência para o funcionamento da máquina pública.

De um lado, existem limitações a serviços e atividades consideradas auxiliares, porém, necessárias à máquina pública para o desempenho de suas funções quando a interrupção possa comprometer a continuidade das políticas públicas e cuja contratação deva estender-se por mais de um exercício financeiro.

De outro lado, a terceirização é recomendada no caso de serviços e atividades de apoio ao funcionamento dos entes públicos relacionados às áreas de conservação, limpeza, segurança, vigilância, transporte, informática, copeiragem, recepção, reprografia, telecomunicação e manutenção de prédios, equipamentos e instalações.

No Poder Legislativo, partindo-se da ótica do controle, o Tribunal de Contas da União (TCU) publicou o Acórdão n. 2132 (BRASIL, 2010), baseandose nas orientações da súmula 331 do TST, recomendando o fim dos contratos 
de mão de obra terceirizada nas empresas estatais ligadas ao governo federal, por meio de um processo meritocrático de concurso público que promova a substituição de servidores terceirizados em atividades fim por servidores públicos ${ }^{6}$.

Ademais, observa-se a partir da ótica legiferante promovida por parlamentares, que projetos de lei sobre terceirização foram apresentados, tanto, na Câmera, quanto, no Senado, demonstrando assim, que as propostas do Poder Legislativo são muitas vezes conflitantes, o que reflete os diferentes interesses sociais presentes.

De um lado, há a apresentação do Projeto de Lei do Senado, n. 422/ 2012, que institui normas relativas à natureza da contratação, controle, transparência, proteção ao trabalhador e vedação à ingerência em atos administrativos das empresas terceirizadas pela Administração Pública Federal, bem como o Projeto de Lei, n. 6.662/2010, da mesma casa, que proíbe órgãos públicos de contratar terceirizados para exercer atribuições inerentes ao seu corpo funcional (BRASIL, 2013).

De outro lado, estão os projetos que buscam regulamentar a terceirização, de número 4.330/2004, apresentado na Câmara dos Deputados, e 087/2010, apresentado no Senado Federal, os quais têm em comum dois pontos defendidos pela CNI - a responsabilidade subsidiária e a universalização da terceirização, abrange, assim qualquer atividade da empresa contratante e não apenas as atividades-fim.

Conclui-se que diante da falta de uma lei específica sobre a terceirização, os avanços jurisprudenciais do TST e STJ, quanto à responsabilidade subsidiária da Administração Pública nestes contratos, repercutem na máquina pública brasileira, embora ainda persista uma urgente necessidade de se editar uma norma legal específica para regular a terceirização em razão da legalidade ou ilegalidade levar em conta a centralidade da definição de atividade-meio, que é excessivamente subjetiva em um contexto de crescente multiplicação, complexidade e interdependência de atividades.

\footnotetext{
${ }^{6}$ Cerca de 145 empresas públicas da administração indireta, sociedades de economia mista e subsidiárias sob a responsabilidade do MPOG apresentaram em novembro de 2012, segundo determinação do Tribunal de Contas da União (TCU), os planos de substituição gradual de servidores terceirizados em atividades-fim por concursados até 2016.
} 


\section{REFERÊNCIAS}

BONFiglioli, J. C. Trabalho Temporário e Terceirização de Serviços: aspectos legais e sociais. São Paulo: Jobcenter, 2011.

BRASIL. Decreto-Lei $\mathbf{n}^{0}$ 200, de 25 de fevereiro de 1967. Dispõe sobre a organização da Administração Federal, estabelece diretrizes para a Reforma Administrativa e dá outras providências. Brasília: Presidência da República, 1967.

BRASIL. Lei $\mathbf{n}^{\mathbf{0}}$ 6.019, de 03 de janeiro de 1974. Dispõe sobre o trabalho temporário nas empresas urbanas, e dá outras providências. Brasília: Presidência da República, 1974.

BRASIL. Lei $\mathbf{n}^{\mathbf{0}} \mathbf{7 . 1 0 2}$, de 20 de junho de 1983. Dispõe sobre segurança para estabelecimentos financeiros, estabelece normas para constituição e funcionamento das empresas particulares que exploram serviços de vigilância e de transporte de valores, e dá outras providências. Brasília: Presidência da República, 1983.

BRASIL. Lei $\mathbf{n}^{\mathbf{0}}$ 8.666, de 21 de junho de 1993. Regulamenta o art. 37, inciso XXI, da Constituição Federal, institui normas para licitações e contratos da Administração Pública e dá outras providências. Brasília: Presidência da República, 1993.

BRASIL. Lei $\mathbf{n}^{\mathbf{0}}$ 8.987, de 13 de fevereiro de 1995. Dispõe sobre o regime de concessão e permissão da prestação de serviços públicos previsto no art. 175 da Constituição Federal, e dá outras providências. Brasília: Presidência da República, 1995.

BRASIL. Lei $\mathbf{n}^{0}$ 9.472, de 16 de julho de 1997. Dispõe sobre a organização dos serviços de telecomunicações, a criação e funcionamento de um órgão regulador e outros aspectos institucionais, nos termos da Emenda Constitucional nº 8, de 1995. Brasília: Presidência da República, 1997.

BRASIL. Ministério do Planejamento, Orçamento e Gestão. Instrução Normativa $\mathbf{n}^{0}$ 2, de 16 de agosto de 2011. Brasília, 2011. 
BRASIL. Ministério do Planejamento, Orçamento e Gestão. Instrução Normativa no 3, de 16 de dezembro de 2011. Brasília: MPOG, 2011.

BRASIL. Tribunal de Contas da União. Acórdão no 2132, de 25 de agosto de 2010. Brasília, 2010.

BRASIL. Tribunal Superior do Trabalho. Projeto regulamenta contratação de serviços terceirizados pela Administração Pública. Notícias do Legislativo, 24 jan. 2013. Disponível em: $<$ www.tst.jus.br/jurisprudencia $>$. Acesso em: 24 jan. 2013.

BRASIL. Tribunal Superior do Trabalho. Orientações jurisprudenciais, de 06 de julho de 2012. Disponível em <www.tst.jus.br/jurisprudencia $>$. Acesso em 23 jan. 2013.

BRASIL. Tribunal Superior do Trabalho. Súmula TST n 331, 31 de maio de 2011. Disponível em <www.tst.jus.br/jurisprudencia>. Acesso em 19/ $01 / 2013$.

BRASIL. Tribunal Superior do Trabalho. Súmula TST n⿳ 256, 30 de Setembro de 1986. Disponível em <www.tst.jus.br/jurisprudencia $>$. Acesso em 19/01/2013.

CORTEZ, J. C. Direito do trabalho aplicado. São Paulo: LTr, 2004.

DI PIETRO, M. S. Z. Parcerias na administração Pública: concessão, permissão, franquia, terceirização, parceria público-privada e outras formas. São Paulo: Atlas, 2006.

DINIZ, J. J. B. O direito e a justiça do trabalho diante da globalização. São Paulo: LTr, 1999.

FILADELFO, G. C. Terceirização ilícita e seus efeitos - cabimento da isonomia salarial. Revista Âmbito Jurídico, v. 14, n. 86, mar., 2011. Disponível em:<www.ambito-juridico. com.br>. Acesso em: 22 jan. 2013. 
HINZ, H. M. A terceirização trabalhista e as responsabilidades do fornecedor e do tomador dos serviços: um enfoque multidisciplinar. Revista do Tribunal Superior do Trabalho, v. 71, n. 2, 2005.

KICH, K. K. Súmula 331 do TST: Análise do instituto normativo e sua importância para a terceirização trabalhista. Revista Âmbito Jurídico, n. 76, maio, 2010. Disponível em: <www.ambito-juridico.com.br $>$. Acesso em: 21 jan. 2013.

MARTINS, S. P. A terceirização e o direito do trabalho. São Paulo: Atlas, 2003.

PASTORE, J. A polêmica sobre a terceirização. Siderurgia: Revista do Instituto Brasileiro de Siderurgia, Rio de Janeiro, nov., 2006.

POCHMANN, M. A Superterceirização do Trabalho. São Paulo: LTR, 2008.

SEKIDO, A. M. Y. Terceirização na Administração Pública: a gestão e a fiscalização dos contratos. 2010. Monografia (Especialização) - Universidade Gama Filha, Brasília, 2010.

SOUTO, M. J. V. Desestatização: Privatização, concessões, terceirizações e regulação. Rio de Janeiro: Editora Lumen Juris, 2001.

SOUTO MAIOR, J. L. S. Terceirização na Administração Pública: uma prática inconstitucional. Revista Justiça do Trabalho, v. 23, n. 273, set., 2006.

SILVA, E. A. Terceirização na Administração Pública: conflitos na legislação, orçamentação e escrituração da despesa. 2008. Monografia (Especialização em Orçamento Público) - Instituto Serzedello Corrêa, Tribunal de Contas da União, Brasília, 2008.

SILVA, P. P. Terceirização nos serviços públicos. Revista do Tribunal Superior do Trabalho, v. 77, n.1, 2011. 
SIROTHEAU, L. O. Nova redação da Súmula 331 do TST e sua aplicabilidade contra os entes públicos. Jus Navigandi, n. 2903, jun., 2011. Disponível em:<http://jus.com.br/artigos/19317>. Acesso em: 24 jan. 2013.

Artigo recebido em 16/09/13 e aprovado para publicação em 21/10/13

Como citar: SENHORAS, Eloi Martins. Controvérsias sobre as relações negociais com o setor público: um estudo sobre a terceirização no Brasil. Scientia Iuris, Londrina, v.17, n.2, p149-166, Dez.2013. DOI: 10.5433/21788189.2013v17n2p149. 